\title{
Alternative Splicing in the Postgenomic Era, edited by Benjamin J. Blencowe and Brenton R. Graveley. 2007, XXIV, Springer, New York. ISBN: 978-0-387-77373-5.
}

Alternative splicing research has been reinvigorated during the genomic era. The availability of large EST data sets that could be mapped to genome sequences allowed bioinformaticists to demonstrate that alternative splicing was far more prevalent than had ever previously been imagined, and this went a long way to explaining the initially embarrassing shortfall in the number of human genes. Properly informed generalizations could now be made about the types of functional consequences arising from alternative splicing, and comparative genomics allowed insights into the evolution of alternative splicing, for example, indicating the surprisingly low extent of conservation of alternative splicing events between mouse and human. A combination of new wet-experimental and computational tools promised the ability to unravel the details of the "RNA code"-the combinations of sequence motifs that dictate under which circumstances a particular exon or splice site will be usedand of the "cellular code"- the complements of splicing regulators in different cells that interpret the RNA code. However, the biochemical and molecular analyses of individual model exons, the workhorse approaches of the previous $\sim 15-20$ years of "pregenomic" alternative splicing research, have not been abandoned. They are still needed to dissect the molecular details of how spliceosome assembly can be impeded or encouraged at particular sites. By harnessing the wealth of new experimental tools and sequence data, it is now becoming possible to test the extent to which findings within individual model systems can be generalized.

Alternative Splicing in the Postgenomic Era sets out to review the current state of the alternative splicing field and to identify the challenges that lie ahead. Surprisingly, it is the first book, pre- or postgenomic, devoted to the topic. The 13 chapters have been well coordinated such that coverage of the field is pretty much complete, while duplication of material between chapters is minimal, which is no mean feat. The topics range from "background" coverage of the structure and dynamics of the nucleus (Carmo-Fonseca) and the

Article published online ahead of print. Article and publication date are at http://www.rnajournal.org/cgi/doi/10.1261/rna.1340908. spliceosome (Moore), to computational analyses of the functional consequences and evolution of alternative splicing (chapters by Lee and Brenner). Blencowe contributes a comprehensive account of techniques for global analysis of alternative splicing, including splice-sensitive microarray platforms, and the new insights that have been enabled by these approaches. A thoughtful chapter by Chasin discusses progress toward the identification of the complete set of splicing regulatory motifs. Graveley's chapter on complex alternative splicing provides a nice example of how comparative genomics can inform traditional molecular analysis-a key example being his own characterization of the secondary structures that control splicing of the huge arrays of Dscam mutually exclusive exons. Chapters by Fu and Chabot, respectively, focus on the main families of splicing regulators-the SR and hnRNP proteins-and have to grapple with the problem of defining exactly what counts as an SR or hnRNP protein. A concise chapter on the Nova proteins, focusing on trailblazing work from the Darnell laboratory, highlights how a range of global and traditional approaches can lead toward the deciphering of RNA codes. The regulation of alternative splicing by signaling pathways was for a number of years a neglected topic. Kristen Lynch describes the rapid progress that has subsequently been made. Kornblihtt discusses the various ways in which transcription by RNA polymerase II can influence splicing outcomes and how the "pausing architecture" of genes therefore constitutes an essential part of the splicing code. The book concludes with a chapter by Tom Cooper on human disease and alternative splicing. Diseases such as myotonic dystrophy and FTDP17 (frontotemporal dementia with parkinsonism linked to chromosome 17) vividly illustrate the importance of correct regulation of alternative splicing. In these cases, there is no "aberrant" splicing in the sense that an unnatural spliced mRNA is produced. Rather the unbalanced ratio of perfectly normal protein isoforms in the wrong biological context leads to disease.

Are there any obvious gaps in coverage? Probably a few, but to my mind they are not serious. Personally, I think a chapter on the sex-determination pathway in Drosophila, which has provided many of the most important insights into mechanisms of splicing repression and activation, would have been 
useful, as well as possibly a dedicated chapter on the applications of transgenic mice in alternative splicing research (for review, see Möröy and Heyd 2007). My main concern when first picking up this book was whether, with the current proliferation of review journals with high production values, a book was even necessary. Indeed, many of the contributors have already authored reviews on the same or similar topics. Moreover, at first glance the quality of the figures varies between chapters, and the small font size is unforgiving to someone in continued denial about the need for reading glasses. Happily though, my fears were allayed. While this volume focuses on the current state of post-genomic alternative splicing research, it does so with a well-grounded appreciation of the pregenomic heritage. Each of the editors-Ben Blencowe and Brent Graveley-has successfully exploited both the classical and the post-genomic tools for investigating alternative splicing. Moreover, many among the distinguished group of authors also have long pregenomic pedigrees in splicing research. A typical journal-based themed collection of reviews would not be able to approach the same breadth and depth of coverage as is achieved here. For these reasons, this book should stand the test of time, despite the current pace of advance and the accompanying inevitability that some details will soon become outdated. An obvious example is in the application of the new generation of deep sequencing technologies. Blencowe's own chapter gives an excellent account of the various technologies for global discovery and analysis of alternative splicing, concluding with an insightful discussion of the potential applications of new sequencing technologies. The first slew of articles using deepsequencing approaches for transcriptome profiling has begun to appear over the past few months, following the publication of the book. But I take this as a healthy sign that this book deals with an active research area that will keep many of us occupied for some time to come. Alternative Splicing in the Postgenomic Era should remain a useful reference volume for the foreseeable future.

\section{REFERENCE}

Möröy, T. and Heyd, F. 2007. The impact of alternative splicing in vivo: Mouse models show the way. RNA. 13: 1155-1171.

Christopher W.J. Smith, Department of Biochemistry, University of Cambridge, 80 Tennis Court Road, Old Addenbrookes Site, Cambridge CB2 1GA, UK; e-mail: cwjs1@ mole.bio.cam.ac.uk; fax: 44-1223-766002. 

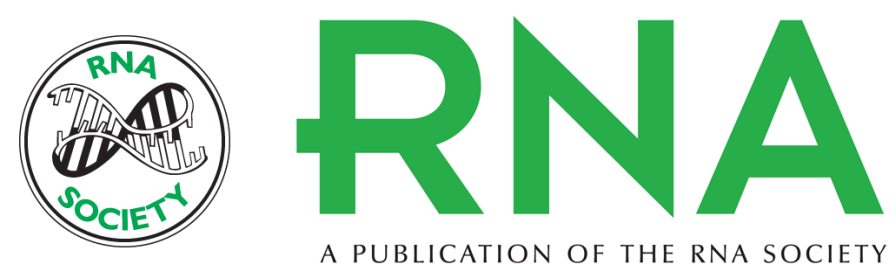

A PUBLICATION OF THE RNA SOCIETY

\section{Alternative Splicing in the Postgenomic Era, edited by Benjamin J. Blencowe and Brenton R. Graveley. 2007, XXIV, Springer, New York. ISBN: 978-0-387-77373-5.}

Christopher W.J. Smith

RNA 2008 14: 2460-2461 originally published online October 22, 2008

Access the most recent version at doi:10.1261/rna.1340908

References This article cites 1 articles, 1 of which can be accessed free at:

http://rnajournal.cshlp.org/content/14/12/2460.full.html\#ref-list-1

License

Email Alerting

Receive free email alerts when new articles cite this article - sign up in the box at the Service top right corner of the article or click here. 